\title{
The Relationship Between Underlying Disease, Type of Acute Respiratory Failure With Outcome in Pulmonary Ward of Dr. M. Djamil Hospital Padang
}

\author{
Nova Indriyani ${ }^{1}$, Russilawati ${ }^{2}$, Oea Khairsyaf $^{3}$, Irvan Medison ${ }^{4}$ \\ \{parupadang@yahoo.com\} \\ Department of Pulmonology and Respiratory Medicine, DR .M. Djamil Hospital/Medical Faculty of \\ Universitas, Andalas, Padang, Indonesia
}

\begin{abstract}
Acute respiratory failure (ARF) is a syndrome of inadequate gas exchange that caused by many underlying disease, particularly respiratory diseases. This condition cause high mortality that influenced by several factors. The aims of this study was to find out the association between underlying disease, type of ARF with the outcome. A cross-sectional study as part of National Registry for ARF that include all patients that had been referred to pulmonary ward of Dr. M. Djamil Hospital Padang with ARF from January to December 2017. During the period of study we found total 58 patients that consist of 40 males and 18 females. The mortality happen on 32 patients $(55.2 \%)$ and the remain 26 patients $(44,8 \%)$ got clinical improvement. There was no association of underlying disease on outcome in patient with ARF. The type of ARF also had no association with the outcome (OR 0, $942(0,295-3,002$ CI 95\%); $p=1,00)$. The rate of mortality among patients with ARF in pulmonary ward, even with high care was still high, in which more than half or they died. The underlying diseases and type of ARF had no impact on outcome.
\end{abstract}

Keywords: Acute Lung Injury, Lung Disease, Respiratory Insufficiency

\section{Introduction}

Acute respiratory failure can be defined as a failure of significant gas exchange capacity in the respiratory system. Failure in gas exchange function in the form of failure in oxidation (hypoxemia) or $\mathrm{CO}_{2}$ elimination (hypercapnia, ventilation failure) or both functions (1), (2). Acute Respiratory Failure is a very serious clinical problem, which is associated with high morbidity, mortality and costs. Morbidity and mortality increase with age and comorbidity. Accurate estimation of ARF incidence are difficult to determine due to non-uniform definitions and heterogeneity of causes and clinical manifestations. It's surprising the huge variability of ARF incidence, in various population-based studies between different continents such as South America (10,1 per 100.000 persons/year), Europe, (17,9 per 100.000 persons/year), Australia (34 per 100.000 persons/year) and USA (78,9 per 100.000 persons/year). Mortality in ARDS patients is still high (3). Mortality in ARF reaches $40 \%$. Patients aged less than 60 years have a better survival rate than elderly patients. Two-thirds of patients who survive post-respiratory failure show impaired lung function. Significant mortality occurs in patients with hypercapnia ARF. Most of these patients have disorders of chronic respiration and comorbid conditions such as cardiopulmonary, renal, hepatic or neurological disorders and malnutrition (4). 
At present, in Indonesia, epidemiologic information about ARF is still limited, and in Dr.M.Djamil Hospital Padang there is no epidemiologic information about ARF.The aims of this study to evaluate the characteristics of ARF patients, the relationship between underlying disease and outcome, and type of ARF and outcome in pulmonary ward of regional referral hospital Padang from January - December 2017.

\section{Materials and Methods}

\subsection{Design}

This was a cross-sectional study and part of a national registry of respiratory failure multi center study.

\subsection{Setting and Sample}

The inclusion criteria of this study were all patients diagnosed with respiratory failure in the Pulmonary department of RSUP Dr.M.Djamil Padang who had complete medical record between the period of January - December 2017.

\subsection{Data Collections}

We collected data from the medical record are age, Body Mass Index, smoking habits, comorbidities, underlying disease and type of ARF. Data were obtained from the national registry of respiratory failure multicenter study records and medical records of patients. There were four groups of underlying diseases in patients treated with respiratory failure called primary diagnosis that involved pulmonary disease (based on International Classification of Disease 10) which was recorded in patient's discharge records, including infection, asthma, Chronic Obstructive Pulmonary Disease, and malignancy.

\subsection{Data Analyzed}

Type of ARF defined to two type, type 1 is hypoxemia ARF that sign with low partial pressure of $\mathrm{O} 2(\mathrm{PaO} 2<60 \mathrm{mmHg})$, oxygen saturation $<91 \%, \mathrm{PaO} 2 / \mathrm{FiO} 2<300$ or decrease $10 \mathrm{mmHg}$ $\mathrm{PaO} 2$ from the baseline (if known), and type 2 is hypercapnia ARF that sign with high partial pressure of $\mathrm{CO} 2(\mathrm{PaCO} 2>50 \mathrm{mmHg}$ with low acidity $\mathrm{pH}<37,5$ or increase $10 \mathrm{mmHg} \mathrm{PaCO} 2$ from the baseline (if known). The outcomes of the patients were a clinical improvement as patient discharge by doctor allowance and death during hospitalized.

\subsection{Ethical considerations}

Ethical clearance was issued by the Ethics Committee of the Faculty of Medicine, Andalas University. Data processing was performed using computer software. The analysis carried out were univariate and bivariate analysis. The bivariate analysis uses chi-square for categorical data, with alternative Fisher Exact test. If the variables more than two and there was an expected value of less than 5, we use alternative test was Kruskal Wallis. We considered p-value $<0,05$ with $95 \%$ CI as statistically significant. 


\section{Results}

The number of subjects in this study was 58 patients with the characteristics and types of comorbidities that can be seen in Table 1 . The sex was dominantly male, 40 subjects $(68.9 \%)$. The mean age was 59,27 $\pm 13,21$. Weight measurement using Body Mass Index, subjects classified as underweight as much as 20 patients $(34,5 \%)$, normal 30 patients $(51,7 \%)$ and overweight 8 patients(13,8\%). In this study, smoking subjects were 39 patients $(67,2 \%)$, and those who did not smoke were 19 patients $(32,8 \%)$. The most common comorbidity in ARF was heart disease.

Table 1. Characteristic data ARF patients

\begin{tabular}{|c|c|c|c|c|c|c|c|}
\hline \multirow[b]{2}{*}{ Subjects characteristic } & \multicolumn{2}{|c|}{ Outcome } & \multirow[b]{2}{*}{ Total } & \multirow[b]{2}{*}{ OR } & \multicolumn{2}{|c|}{$95 \% \mathrm{CI}$} & \multirow[b]{2}{*}{$\begin{array}{c}\mathrm{p} \\
\text { value }\end{array}$} \\
\hline & $\begin{array}{l}\text { Clinically } \\
\text { improved } \\
\mathrm{f}(\%)\end{array}$ & $\begin{array}{l}\text { Died } \\
\mathrm{f}(\%)\end{array}$ & & & Lower & Upper & \\
\hline \multicolumn{8}{|l|}{ Sex } \\
\hline Male & $20(34,5)$ & $20(34,5)$ & $40(69,0)$ & \multirow{2}{*}{2} & \multirow{2}{*}{0,627} & \multirow{2}{*}{6,377} & \multirow{2}{*}{0,371} \\
\hline Female & $6(10,3)$ & $12(20,7)$ & $18(31,0)$ & & & & \\
\hline \multicolumn{8}{|l|}{ Education } \\
\hline Low education & $6(10,3)$ & $15(25,9)$ & $21(36,2)$ & \multirow{2}{*}{0,34} & \multirow{2}{*}{0,108} & \multirow{2}{*}{1,07} & \multirow{2}{*}{0,109} \\
\hline High education & $20(34,5)$ & $17(29,3)$ & $37(63,8)$ & & & & \\
\hline \multicolumn{8}{|l|}{ Occupation } \\
\hline Working & $20(34,5)$ & $26(44,8)$ & $46(79,3)$ & \multirow{2}{*}{0,77} & \multirow{2}{*}{0,215} & \multirow{2}{*}{2,747} & \multirow{2}{*}{0,937} \\
\hline Not working & $6(10,3)$ & $6(10,3)$ & $12(20,7)$ & & & & \\
\hline \multicolumn{8}{|l|}{ Smoking habit } \\
\hline Smoking & $19(32,8)$ & $20(34,5)$ & $39(67,2)$ & \multirow{2}{*}{1,63} & \multirow{2}{*}{0,529} & \multirow{2}{*}{5,011} & \multirow{2}{*}{0,569} \\
\hline Not smoking & $7(36,8)$ & $12(63,2)$ & $19(32,8)$ & & & & \\
\hline \multicolumn{8}{|l|}{ BMI } \\
\hline Normal* & $10(17,2)$ & $20(34,5)$ & $30(51,7)$ & 0 & ref & Ref & \multirow{3}{*}{0,175} \\
\hline Underweight & $12(20,7)$ & $8(13,8)$ & $20(34,5)$ & 3 & 0,928 & 9,697 & \\
\hline Overweight & $4(6,9)$ & $4(6,9)$ & $8(13,8)$ & 1,5 & 0,288 & 7,807 & \\
\hline \multicolumn{8}{|l|}{ Comorbidities } \\
\hline No comorbid* & $6(10,3)$ & $6(57,1)$ & $14(24,1)$ & 0 & ref & Ref & \multirow{6}{*}{0,473} \\
\hline Hypertension & $2(3,5)$ & $2(3,5)$ & $4(6,9)$ & 0,75 & 0,081 & 6,958 & \\
\hline $\begin{array}{l}\text { Diabetes } \\
\text { Mellitus }\end{array}$ & $2(3,5)$ & 0 & $2(3,5)$ & 0 & 0 & . & \\
\hline Heart disease & $7(12,1)$ & $9(15,5)$ & $16(27,6)$ & 0,96 & 0,227 & 4,102 & \\
\hline Renal disease & $1(1,7)$ & $5(8,6)$ & $6(10,3)$ & 3,75 & 0,342 & 41,08 & \\
\hline Others & $8(13,8)$ & $8(13,8)$ & $16(27,6)$ & 0,75 & 0,177 & 3,173 & \\
\hline
\end{tabular}




\subsection{Relationship between underlying diseases and outcome ARF}

We found the most common underlying disease was COPD, as many as 28 people $(48,3 \%)$, followed by infection 20 people (34,5\%), malignancy 6 people (10.3\%) and asthma 4 people (6.9\%) (Table.2). In another hand, death during hospitalized mostly happened in infection patients, (nine pneumonia and six tuberculosis). Pneumonia patients who suffered ARF had mortality rate nine from fourteen $(15,5 \%)$. While in tuberculosis patient most patient with ARF died during hospitalized. In COPD patients the mortality rate achieved 46\% (13 from 28 patients). Statistical analysis found out there was no relationship between underlying diseases with the outcome of ARF (value $=0,139 ; \mathrm{CI} 95 \%$ ).

Table 2. The relationship between underlying disease with outcome ARF

\begin{tabular}{|c|c|c|c|c|c|c|c|}
\hline \multirow[b]{2}{*}{$\begin{array}{l}\text { Underlying } \\
\text { disease }\end{array}$} & \multicolumn{2}{|l|}{ Outcome } & \multirow[b]{2}{*}{ Total } & \multirow[b]{2}{*}{ OR } & \multicolumn{2}{|c|}{$95 \% \mathrm{CI}$} & \multirow[b]{2}{*}{ p-value } \\
\hline & $\begin{array}{l}\text { Clinically } \\
\text { improved } \\
\mathrm{f}(\%)\end{array}$ & $\begin{array}{l}\text { Died } \\
\mathrm{f}(\%)\end{array}$ & & & Lower & Upper & \\
\hline Infection* & $5(8,6)$ & $15(25,9)$ & $20(34,5)$ & 0,000 & ref & Ref & \multirow{4}{*}{0,139} \\
\hline Asthma & $3(5,2)$ & $1(1,7)$ & $4(6,9)$ & 0,111 & 0,009 & 1,326 & \\
\hline COPD & $15(25,9)$ & $13(22,4)$ & $28(48,3)$ & 0,289 & 0,082 & 1,014 & \\
\hline Malignancy & $3(5,2)$ & $3(5,2)$ & $6(10,3)$ & 0,333 & 0,050 & 2,214 & \\
\hline
\end{tabular}

*6 tuberculosis and 14 pneumonia

\subsection{Relationship between type with the outcome of ARF}

The type of ARF that was determined based on blood gas analysis, in this study, type II ARF (hypercapnia) was seen more as many as 42 people (72.43\%), while type I ARF(hypoxemia) as many as 16 people (Table.3). Statistical analysis found out there was no relationship between ARF type and the outcome $(\mathrm{OR}=0,942 ; \mathrm{CI95} \% 0,295-3,002 ; \mathrm{p}=1,00)$.(Table3)

Table 3. The relationship between type with the outcome of ARF

\begin{tabular}{|c|c|c|c|c|c|c|c|}
\hline \multirow{2}{*}{$\begin{array}{c}\text { Type of } \\
\text { Respiratory } \\
\text { Failure }\end{array}$} & \multicolumn{2}{|l|}{ Outcome } & \multirow[b]{2}{*}{ Total } & \multirow[b]{2}{*}{ OR } & \multicolumn{2}{|l|}{$95 \% \mathrm{CI}$} & \multirow[b]{2}{*}{$P$ value } \\
\hline & $\begin{array}{l}\text { Clinically } \\
\text { improved } \\
\mathrm{N}(\%)\end{array}$ & $\begin{array}{l}\text { Died } \\
\text { N (\%) }\end{array}$ & & & Lower & Upper & \\
\hline Type 1 & $7(12,1)$ & $9(15,5)$ & $16(27,6)$ & & & & \\
\hline Type 2 & $19(32,8)$ & $23(39,7)$ & $42(72,4)$ & 0,942 & 0,295 & 3.002 & 1.00 \\
\hline
\end{tabular}

\section{Discussion}

Majority of the subjects in the current study were males with mean age of the patients at $59,27 \pm 13,21$ years. The current's study finding almost similar to Sheu's study in which they found the gender predominantly male and the median of age was 60 years old (5). Luhr 's also report a similar finding in the mean of age which is $62,3 \pm 16,1$ (6). This finding slightly different with Magazine's report in South India that reviewed 150 patients Acute Respiratory Distress Syndrome (ARDS) in tertiary care. There was a similarity in gender with male dominantly. 
However, the mean of age in the current study was older compared to Magazine's (mean $42,9 \pm 13,9$ years) (7). This differences might happen because of the different inclusion criteria that in South India study included bilateral infiltrate in the chest radiograph. This criterion could lead most of the eligible subjects had an infection as the underlying disease. In another hand the current study got COPD as the most common underlying disease.

The mortality rate of ARF patient in the current study was 55,17\%. This finding is most similar with other studies, Ando's study in Japan 53,19\% and Magazine's study in South India $44 \%$ (8). The similarity between these studies could cause by many factors. In other studies the subjects mostly geriatric patients with comorbidity. This condition generally caused mortality rate higher. While Magazine studies mostly involved subject with infections that also have a high mortality rate. The higher mortality in ARF patients with infection as an underlying disease also reported by Sheu, in which the mortality rate ARF patients with sepsis more than two folds compare two ARF patient without sepsis (5).

This finding in current study more than a half of our patients had a preexisting comorbid $58,6 \%(\mathrm{n}=34)$, mostly heart disease $(27,6 \%)$ and there is no relationship between preexisting comorbidity and outcome ARF patients. Similar to Ando's report that revealed the prognosis acute lung injury and ARDS there is no association between comorbidity with outcome ARF (8). In the current study, $41,4 \%$ of nonsurvivors and only $34,5 \%$ of the survivors had a preexisting comorbid illness. Similar results were noted in Sheu's study, where the occurrence of comorbidities was more frequent in nonsurvivors (5). Adler's study also reported morbidity in patients surviving acute hypercapnic respiratory failure might be associated with poor outcome (9).

In current study, most common underlying disease for ARF was COPD $(48,3 \%)$ followed by infection $(34,5 \%)$, malignancy $(10,3 \%)$ and asthma $(6,9 \%)$. Another national survey was done in U. The most common etiologies of ARF among medical patients were pneumonia, Congestive Heart Failure, ARDS, COPD exacerbation and sepsis (10). Because so many underlying causes contribute to it, respiratory failure is a common and major cause of illness and death. However, it is hard to quantify because the cause of death is more likely to be listed as pneumonia, COPD, or another underlying condition, rather than respiratory failure.

In hypercapnic ARF(i.e., pump failure) an imbalance exists between the load imposed on the respiratory muscles and the capacity of the muscle pump, this category includes patients with exacerbation of COPD. Hypoxaemic ARF covers miscellanea of the cause of lung damage including acute cardiogenic pulmonary edema, infection (i.e., pneumonia) and trauma. ARF is a frequent cause of severe hypoxemia (11). However, in the current study, there was no significant relationship between the type of respiratory failure and outcome of respiratory failure.

The current study still has a limitation, in the case caused by collecting data in a tertiary care facility so that mostly patient had a very severe condition.

\section{Conclusion}

The rate of mortality among patients with respiratory failure in the pulmonary ward, even with high care was still high, in which more than half or they died. The underlying diseases and type of respiratory failure had no impact on the outcome. Chronic Obstructive Pulmonary Disease is the most common underlying disease in the causation of respiratory failure in our hospital. Presence of preexisting comorbidity is frequently associated with poor survival. 


\section{References}

[1] Suh, E. and Hart, N. (2012). Respiratory failure. Medicine, 40(6), pp. 293-297.

[2] Belda, F., Soro,M. and Ferrando,C. (2013). Pathophysiology of respiratory failure. Trends in Anaesthesia and Critical Care, 3(5),a pp. 265-269.

[3] Rezoagli,E., Fumagalli,R. And Bellani, G. (2017). Definition and epidemiology of acute respiratory distress syndrome. Annals of Translational Medicine, 5(14), pp.282.

[4] Lewandowsky,K. (2003). Contributions to the epidemiology of acute respiratory failure. Critical Care, 7(4), pp.288-290.

[5] Sheu,c., Gong, M., Zhai, R., Chen, F., Bajwa , E., Clardy, P., et al. (2010). Clinical characteristics and Outcomes of sepsis - Related vs Non-Sepsis-Related ARDS. Chest, 138(3), pp.559-567.

[6] Luhr, O., Antonsen, K., Karlsson, M., Aardal, S., Thorsteinssson, A., Frostell, C.and Bonde,J.(1999).

[7] Magazine, R., Rao, S., Chogtu, B., Venkateswaran, R., Shahul, H. and Goneppanavar, U. (2017). Epidemiological profile of acute respiratory distress syndrome patients : A tertiary care experience. Lung India, 34(1), pp.38.

[8] Ando, K., Doi, T., Y. Moody,S., Ohkuni, Y., Sato, S. and Kaneko, N.(2012). The effect of Comorbidity on the prognosis of acute lung injury and acute respiratory distress syndrome. Internal Medicine, 51(14), pp. 1835 - 1840.

[9] Adler,D., Pepin, J., Dupuis-Lorezon, E., Espa-cervena, K., Merlet-Violet, R., Muller, H., et al. (2017). Comorbidities and Subgroups of patient surviving severe acute hypercapnic respiratory failure in Intensive Care Unit. Journal AJRCCM. 196(2), pp.200 (2017).

[10] Stefan, M., Shieh, M., Pekow, P., Rothberg, M., Steingrub, J., Lagu, T. And Lindenauer, P.(2018). Epidemiology and outcomes of respiratory failure in the United States, 2001 to 2009; A national survey.

[11] Scala, R. And Heunks, L. (2018). Highlights in acute respiratory failure. European Respiratory Review, 27(147), p.180008. 